\title{
Intestinal Epithelial Cell-Derived CD83 \\ Contributes to Regulatory T-Cell Generation and Inhibition of Food Allergy
}

\author{
Yong Yu ${ }^{a}$ Qiao-Ruo Jin ${ }^{b, c}$ Yang Mi ${ }^{a}$ Jiang-Qi Liu ${ }^{d}$ Zhi-Qiang Liu ${ }^{d}$ \\ Shuai Wang $^{d}$ Zhi-Gang Liu ${ }^{c}$ Ping-Chang Yang ${ }^{b, c}$ Peng-Yuan Zheng ${ }^{a}$ \\ aDepartment of Gastroenterology, Fifth Hospital of Zhengzhou University, Zhengzhou, China; ${ }^{\mathrm{b}}$ Guangdong \\ Provincial Key Laboratory of Regional Immunity and Diseases, Shenzhen, China; ${ }^{C}$ Research Center of Allergy

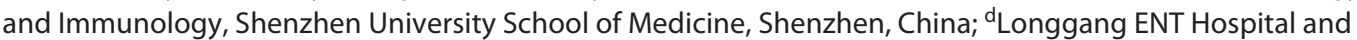 \\ Shenzhen ENT Institute, Shenzhen, China
}

\section{Keywords}

Food allergy · Intestine · Epithelial cell · T lymphocyte · Immunotherapy

\begin{abstract}
The mechanism of generation of antigen-specific regulatory T cells (Treg) is not fully understood yet. This study aimed to investigate the role of intestinal epithelial cell (IEC)-derived CD83 in the Treg generation in the intestine. In this study, the role of CD83 in the generation of Tregs was assessed in a cell-culture model and a food allergy (FA) mouse model. We found that mouse IECs expressed CD83; its levels were markedly lower in sensitized mice. Mice with CD83deficient IECs failed to induce Tregs in the intestine. CD83 promoted the transforming growth factor- $\beta$-inducible early gene 1 (TIEG1) expression in CD4 ${ }^{+} \mathrm{T}$ cells. Toll-like receptor 4 (TLR4)/myeloid differentiation protein-2 (MD-2) complex mediated the effects of CD83 on the expression of TIEG1. Activation of the CD83/TLR4/MD-2/TIEG1 promoted the Treg generation. Concomitant administration of CD83 and specific antigens, but not either one alone, efficiently inhibited experimental FA via inducing the Treg generation in the intestine. In Conclusion, IEC expresses CD83 that is low in
\end{abstract}

karger@karger.com www.karger.com/jin

Karger!"
(C) 2021 The Author(s)

Published by S. Karger AG, Base

This is an Open Access article licensed under the Creative Common Attribution-NonCommercial-4.0 International License (CC BY-NC) (http://www.karger.com/Services/OpenAccessLicense), applicable to the online version of the article only. Usage and distribution for commercial purposes requires written permission. sensitized mice. Concomitant administration of CD83 and specific antigens efficiently inhibits $F A$ in a murine model via inducing Tregs in the intestine. The data suggest that CD83 has translation potential in the treatment of FA.

(c) 2021 The Author(s)

Published by S. Karger AG, Basel

\section{Introduction}

Food allergy (FA) is an aberrant immune response to the innocuous food antigens by the intestinal immune system. The FA clinical symptoms vary from mild abdominal discomfort to the life-threatening anaphylactic shock [1]. Clinically, to avoid ingesting, the allergic foods are expected to prevent FA attacks; this has achieved good results in patients sensitized to peanuts [2-4]. The FA prevalence is estimated $2-6 \%$ worldwide. Therefore, FA has become a public health issue in the world [4]. It is necessary to further investigate the FA pathogenesis and invent novel and effective remedies to be used for FA treatment [1].

Yong Yu and Qiao-Ruo Jin contributed equally to this work.
Correspondence to:

Peng-Yuan Zheng, pengyuanzheng@163.com 
Pathologically, FA subjects present intolerance to allergic food antigens. In other words, FA subjects have a breakdown immune tolerant system to allergic food antigens [5]. The immune tolerant functions are mainly maintained by immune regulatory $\mathrm{T}$ cells (Treg) and regulatory $\mathrm{B}$ cells [6]. Upon activation, Tregs or/and regulatory B cells release immune regulatory mediators, such as transforming growth factor (TGF)- $\beta$ and interleukin (IL)-10, to suppress other immune cell activities [7]. It is recognized that the T helper (Th)-2 polarization plays a central role in the FA pathogenesis $[1,4]$. Intestinal Th2 polarization indicates a condition that the intestinal tissues are overpopulated by Th2 cells and saturated with high levels of Th2 cytokines $[1,4]$. Such a condition mirrors that the intestinal immune tolerance system is dysfunctional. Low Treg frequency was observed in the local tissues of subjects with immune disorders [7]. Yet, the causative factors for immune tolerance system dysfunction are not fully understood.

The forkhead protein-3 (Foxp3) is the transcription factor of a subtype of Treg. Since the Foxp3 deficiency causes severe immune inflammation [8], the $\mathrm{CD} 4^{+}$ Foxp $3^{+}$Tregs have been attracting more attention than other Treg subtypes. To generate Tregs to be used as a "living drug" in the suppression of immune disorders has been studied for years, by which it is expected to restore the immune tolerance in the lesion tissues to reach a solution for the diseases [1]. Yet, factors regulating the Foxp3 expression are not fully elucidated.

Recent reports indicate that $\mathrm{CD} 83$ has immune regulatory functions [9]. CD83 belongs to the immunoglobulin superfamily and has membrane-bound and soluble, 2 forms [9]. It is reported that CD83 can induce indoleamine 2,3-dioxygenase production [10], which is one of the immune-suppressive mediators produced by Tregs [11]. CD83 is well expressed in dendritic cells (DCs) and used as one of the DC markers. Together with membraneassociated RING-CH ubiquitin ligases, CD83 is involved in MHC II ubiquitination that plays an important role in the T-cell thymus selection [12]. It seems that CD83 has immune regulatory capacity and has translation potential to be used in the treatment of immune disorders; thus, its cellular signal transduction pathways need to be in-depth investigated [13].

Based on the information above, we hypothesize that CD83 may contribute to the Treg generation to elicit immune regulatory effects in the intestine on suppressing the FA response. To test the hypothesis, we assessed the CD83 expression in intestinal epithelial cells (IECs). The role and mechanisms of CD83 in facilitating the Treg generation in the intestine were investigated.

\section{Materials and Methods}

\section{Reagents}

Antibodies against TGF- $\beta$ (ab190503), EpCAM (ab71916) with or without labeled with PE, and TLR4/MD-2 complex were purchased from Abcam (Cambridge, MA, USA). Antibodies for flow cytometry, including CD3 (Alexa Fluor ${ }^{\circledR} 488$ ), CD45 (Alexa Fluor $^{\circledR}$ 546), CD25 (Alexa Fluor ${ }^{\circledR}$ 594), CD4 (Alexa Fluor ${ }^{\circledR}$ 647), CD83 (Alexa Fluor ${ }^{\circledR} 488$ ), Foxp3 (Alexa Fluor ${ }^{\circledR} 488$ ), CD11c (Alexa Fluor ${ }^{\circledR}$ 546), CRISPR kits of TIEG1, MD-2 and TLR4, antibodies of CD83 (Clone\#: F-5), IL-10 (A-2), neuropilin (A-12), TIEG1 (95-D), TLR4 (25), Foxp3 (F-9), were purchased from Santa Cruz Biotech (Santa Cruz, CA, USA). Antibody against MD-2 was purchased from Biorbyt (Cambridge, UK). Recombinant sCD83 (comprised of the amino acids Met22-Ala134 with a 6His C-terminal tag) CD40L protein and monoclonal anti-CD25 antibody was provided by Sangon Biotech (Shanghai, China). enzymelinked immunosorbent assay (ELISA) kits of ovalbumin (OVA)specific IgE, IL-4, IL-5, and IL-13 were purchased from Dakewe BioMart (Beijing, China). FITC-dextran $(40 \mathrm{kDa})$ and OVA were purchased from Sigma Aldrich (St. Louis, MO, USA). Reagents and materials for RT-qPCR and Western blotting were purchased from Invitrogen (Carlsbad, CA, USA).

\section{Mice}

$\mathrm{BALB} / \mathrm{c}$ and $\mathrm{C} 57 \mathrm{BL} / 6$ mice (6-8-week old) were purchased from the Beijing Experimental Animal Center. DO11.10 mice were purchased from Jackson Laboratory (Bar Harbor, ME, USA). Mice were maintained in a specific pathogen-free facility at Zhengzhou University with accessing water and food freely. Mice with CD83deficient IECs and mice with TIEG1-deficient $\mathrm{CD} 4^{+} \mathrm{T}$ cells were developed by Beijing Agricultural University Animal Institute (Beijing, China). The description of the gene knockout mice is presented in supplementary materials of this paper.

Preparation of Single Cells in the Mouse Intestinal Tissues

Upon the sacrifice, the small intestinal segments were excised from mice. The tissues were cut into small pieces and incubated with collagenase IV $(1 \mathrm{mg} / \mathrm{mL})$ at $37^{\circ} \mathrm{C}$ for 30 min with mild agitation. Single cells were filtered through a metal mesh $(70 \mu \mathrm{m})$ and collected by centrifugation at $1,000 \mathrm{~g}$ for $5 \mathrm{~min}$.

\section{$C D 4^{+} C D 25^{-}$-Cell Purification}

To prepare single splenocytes, the mouse spleen was excised, cut into small pieces, and incubated with collagenase IV $(1 \mathrm{mg}$ / $\mathrm{mL}$ ) for $20 \mathrm{~min}$ at $37^{\circ} \mathrm{C}$. A red blood cell lysis buffer was then added to the lysates. Single cells were filtered through a metal mesh (70 $\mu \mathrm{M})$; splenocytes were collected by centrifugation at $1,000 \mathrm{~g}$ for 5 min. To purify $\mathrm{CD} 4^{+} \mathrm{CD} 25^{-} \mathrm{T}$ cells, splenocytes were stained with fluorochrome-labeled antibodies of CD3 (Alexa Fluor ${ }^{\circledR} 488$ ), CD45 (Alexa Fluor ${ }^{\circledR}$ 546), CD4 (Alexa Fluor ${ }^{\circledR}$ 647), and CD25 (Alexa Fluor ${ }^{\circledR} 594$ ) at $1 \mu \mathrm{g} / \mathrm{mL}$ of each for $30 \mathrm{~min}$ at $4^{\circ} \mathrm{C}$. With a FACS Aria II Flow Cytometer (BD Bioscience), CD $25^{+}$cells were gated out first. From the remained cells, CD $45^{+} \mathrm{T}$ cells were gated; $\mathrm{CD}^{+}{ }^{+} \mathrm{CD} 4^{+}$cells were then further gated and sorted for further experiments. Cell purity was assessed by flow cytometry. If the purity did not reach $95 \%$ or over, the purification was repeated with the cells. 
Depletion of TIEG1, TLR4, and MD-2 Expression in $C D 4^{+} T$

Cells

Single $\mathrm{CD} 4^{+} \mathrm{T}$ cells were prepared with treated with commercial CRISPR reagent kits for TIEG1 or TLR4 or MD-2 depletion following the manufacturer's instructions. The gene depletion effects were assessed $48 \mathrm{~h}$ later by flow cytometry and Western blotting.

OVA-Specific Inducible Treg Generation in vitro

$\mathrm{CD}^{+}{ }^{+} \mathrm{CD}_{25}{ }^{-} \mathrm{T}$ cells were isolated from the DO11.10 mouse spleen, cultured $\left(10^{6}\right.$ cells $\left./ \mathrm{mL}\right)$ in the presence of DC, and exposed to OVA $(20 \mu \mathrm{g} / \mathrm{mL})$ or/and CD83 $(1 \mu \mathrm{g} / \mathrm{mL})$, IL-2 $(20 \mathrm{ng} / \mathrm{mL})$ in the presence of $\mathrm{DC}$ for 5 days. Medium together with the reagents was changed on day 3 . The cells were analyzed by flow cytometry to assess the Treg generation efficiency.

\section{FA Mouse Model Development}

$\mathrm{BALB} / \mathrm{c}$ mice (6 mice per group) were subcutaneously injected with OVA $(0.2 \mathrm{mg} /$ mouse $)$ mixed in $0.1 \mathrm{~mL}$ alum in the back skin on day 0 and day 7 , respectively. Mice were gavage-fed with OVA ( $1 \mathrm{mg} /$ mouse in $0.1 \mathrm{~mL}$ saline) on day 9 , day 11 , and day 13 , respectively. Mice were challenged with OVA ( $5 \mathrm{mg} /$ mouse in 0.1 $\mathrm{mL}$ saline) on day 15 followed by a FA response assessment or treated with the CD83/OVA therapy as described below.

Assessment of FA Response

On day 15 , or after the CD83/OVA therapy, mice were fed with OVA ( $5 \mathrm{mg} / \mathrm{mouse}$ in $0.1 \mathrm{~mL}$ saline). Diarrhea was recorded within $2 \mathrm{~h}$ after OVA challenge. Core temperature was recorded $30 \mathrm{~min}$ after OVA challenge. Mice were sacrificed $2 \mathrm{~h}$ after OVA challenge by snap capitation. The blood was collected; the serum was isolated from the blood samples and subjected to determine the levels of specific IgE and mouse mast cell protease-1 (mMCP1) by ELISA with commercial reagent kits following the manufacturer's instruction. Small intestinal segments were excised from each mouse; a portion of the intestine was used to extract proteins; the rest of intestinal tissues were used to isolate single cells (see above). Levels of IL-4, IL-5, and IL-13 in intestinal tissue protein extracts were determined by ELISA. To assess the intestinal epithelial barrier permeability, mice were fed with FITC-dextran $(10 \mathrm{mg} / \mathrm{mouse}$ mixed in the OVA solution used in the last challenge). Two hours later, mice were sacrificed, and the blood was collected; the FITCdextran levels in the serum were determined by fluorospectrometric analysis.

Inhibition of FA Response in a Murine Model by Concomitant Administration with CD83 and OVA

From day 14 (1 day after the last challenge with a specific antigen, OVA), sensitized mice were fed with OVA ( $1 \mathrm{mg} / \mathrm{mouse})$ or/ and CD83 (0.1 mg/mouse) in $0.1 \mathrm{~mL}$ saline daily for 7 consecutive days. One day after the last treatment, mice were challenged with the specific antigen (OVA, $5 \mathrm{mg} / \mathrm{mouse}$ in $0.1 \mathrm{~mL}$ saline). The FA responses were assessed as described above. To verify the results, control experiments were designed, in which a group of sensitized mice with TIEG1-deficient CD4 ${ }^{+} \mathrm{T}$ cells was treated with both CD83 and OVA; a group of sensitized mice was peritoneally injected with anti-CD25 Ab (PC61; $0.25 \mathrm{mg} / \mathrm{mouse}$; control mice were treated with isotype $\operatorname{IgG}) 3$ days prior to the treatment with CD83 and OVA, and a group of sensitized mice was treated with CD83 and BSA (a control antigen).

CD83 Facilitates Treg Generation

\section{Results}

IECs Express CD83 that Is Lower in Sensitized Mice

Small intestinal segments were excised from naive mice and sensitized mice, single cells were prepared from the tissues and analyzed by flow cytometry. We found that $\mathrm{CD} 3^{+}$cells in both IEC department and non-IEC department. A significantly smaller number of $\mathrm{CD} 83^{+}$ IECs was detected in the sensitized mice than that in naive control (NC) mice (Fig. 1a, b). CD83 ${ }^{+}$cells were also detected in non-IECs, including $\mathrm{CD}^{+}{ }^{+} \mathrm{T}$ cells, B cells, DCs, macrophages, eosinophils, and mast cells, the number of which was comparable between sensitized mice and NC mice (online suppl. Fig. 1; for all online suppl. materials, see www.karger.com/doi/10.1159/000515332). We also purified IECs from the single cells by flow cytometry cell sorting and analyzed by RT-qPCR and Western blotting. The results showed that the $\mathrm{mRNA}$ and protein levels of CD83 in sensitized mice were significantly lower than that in NC mice (Fig. 1c, d). By immunohistochemistry, CD83-positive IECs and some cells in lamina propria were observed, which were markedly fewer in the FA group (Fig. 1e). The results indicate that IECs express CD83; its levels are significantly lower in sensitized mice.

\section{FA Intestinal Tissues Have Fewer Tregs that Are}

Positively Correlated with CD83 Levels in IECs

We next looked into a possible association between the CD83 expression in IECs and the Treg frequency in the intestinal tissues. Small intestinal segments were excised from NC mice and sensitized mice; lamina propria mononuclear cells (LPMCs) were isolated and analyzed by flow cytometry. The results showed that the Treg counts in sensitized mice were significantly less than that in $\mathrm{NC}$ mice (Fig. 2a, b). A positive correlation was detected between the Treg counts and IEC CD83 expression (Fig. 2c), but no correlation was detected between Treg counts and LPMC CD83 expression (Fig. 2d). The results show a dramatic Treg reduction in the FA intestine that may be associated with the CD83 reduction in IECs of sensitized mice.

\section{Mice with CD83-Deficient IECs Fail to Induce Tregs}

Wild-type mice and mice with CD83-deficient IECs (KO mice) (online suppl. Fig. 2) were treated with a Treg generation protocol by gavage-feeding with OVA daily for 1 week. After the sacrifice, LPMCs were prepared and analyzed by flow cytometry. The results showed that treating wild-type mice with OVA for 1 week markedly increased the Treg counts in the intestine, while signifi- 


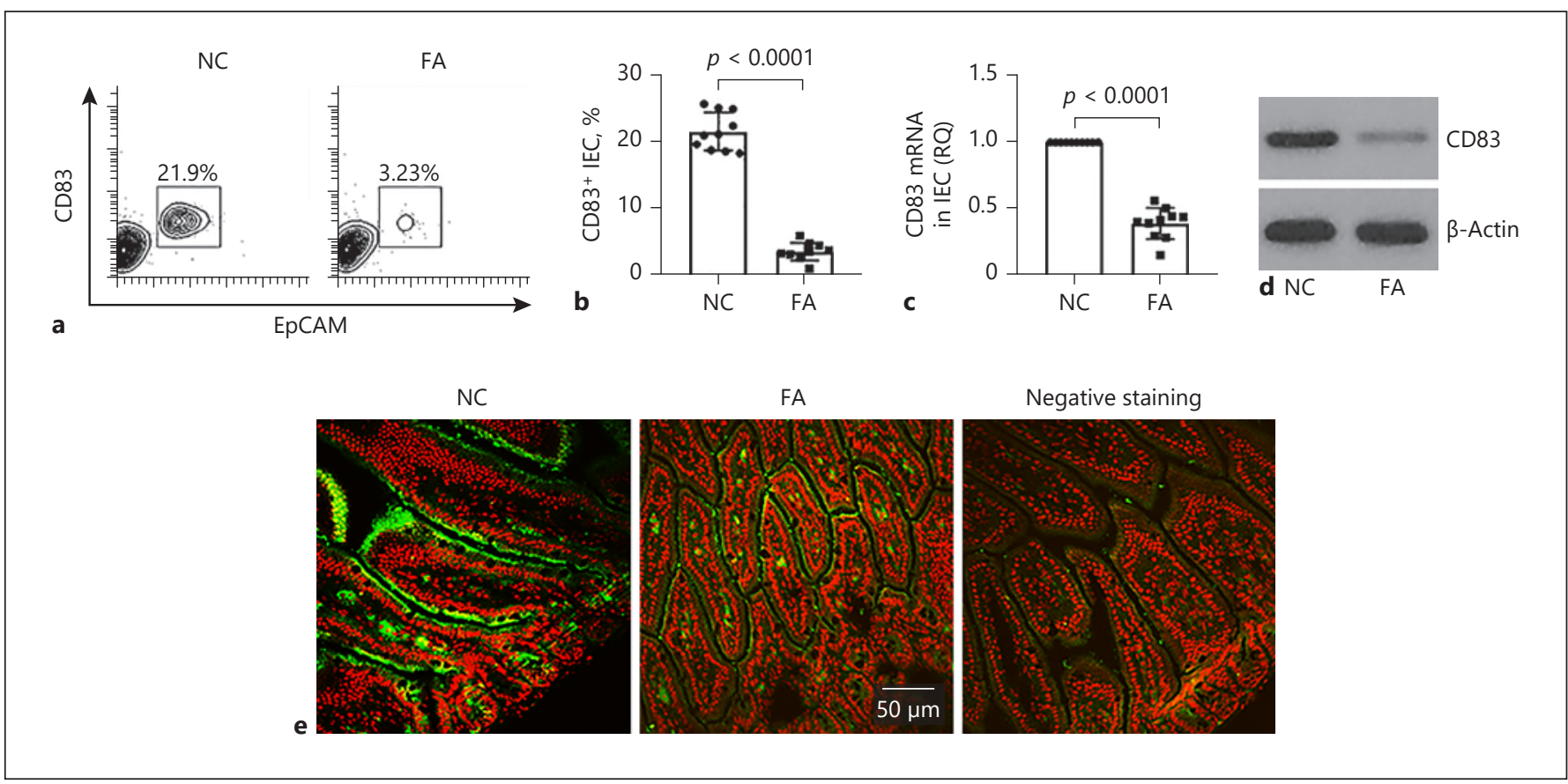

Fig. 1. CD83 expression levels are low in FA mouse IECs. Small intestinal tissues were sampled from NC mice $(n=10)$ and FA mice $(n=10)$. a Single cells were prepared with the samples and analyzed by flow cytometry. The gated plots show $\mathrm{CD} 83^{+}$IECs (EpCAM is a molecular marker of IEC). $\mathbf{b}$ The bars show summarized $\mathrm{CD} 83^{+}$IEC counts. c, d IECs were purified; total RNA and total proteins were extracted from the cells and analyzed by RTqPCR and Western blotting. The bars show CD83 mRNA levels in
IECs (c); the immunoblots show CD83 protein levels in IECs (d). e Representative immunohistochemistry images show CD83-positive staining (in green) in IECs and some cells in the lamina propria. The data of bars are presented as mean \pm SEM of 10 mice per group. Each sample was analyzed in triplicate. Statistics: Student's $t$ test. NC, normal control; FA, food allergy; IECs, intestinal epithelial cells.

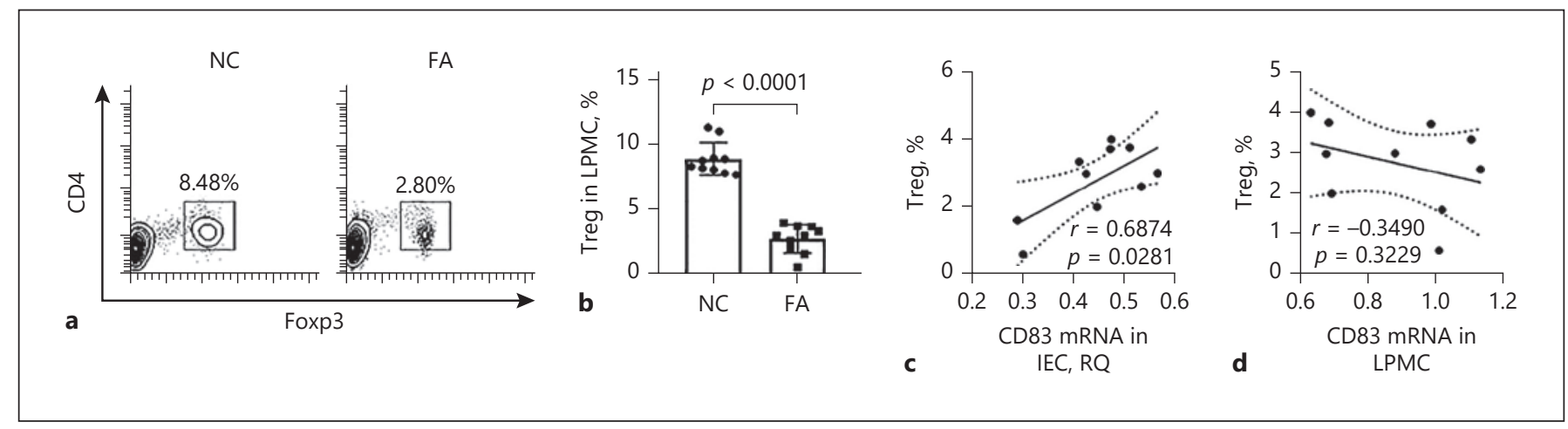

Fig. 2. Assessment of intestinal Treg frequency and its association with IEC-derived CD83 LPMCs were isolated from NC mice and FA mice; the cells were analyzed by flow cytometry. a The gated dot plots show $\mathrm{CD}^{+}$Foxp $^{+}$Tregs (these cells were also CD25 $5^{+}$; not shown). $\mathbf{b}$ The bars show LPMC Treg count mean \pm SEM from 10 mice per group. c, d The scatter plots show positive correlation between Treg counts in the intestine and IEC CD83 expression but not in LPMC CD83 expression. Each sample was analyzed in triplicate. Statistics: Student's $t$ test (b) and the Pearson correlation assay $(\mathbf{c}, \mathbf{d})$. CD83 mRNA data are presented in Fig. 1. Treg, regulatory T cell; IECs, intestinal epithelial cells; LPMCs, lamina propria mononuclear cells; NC, naive control; FA, food allergy. 


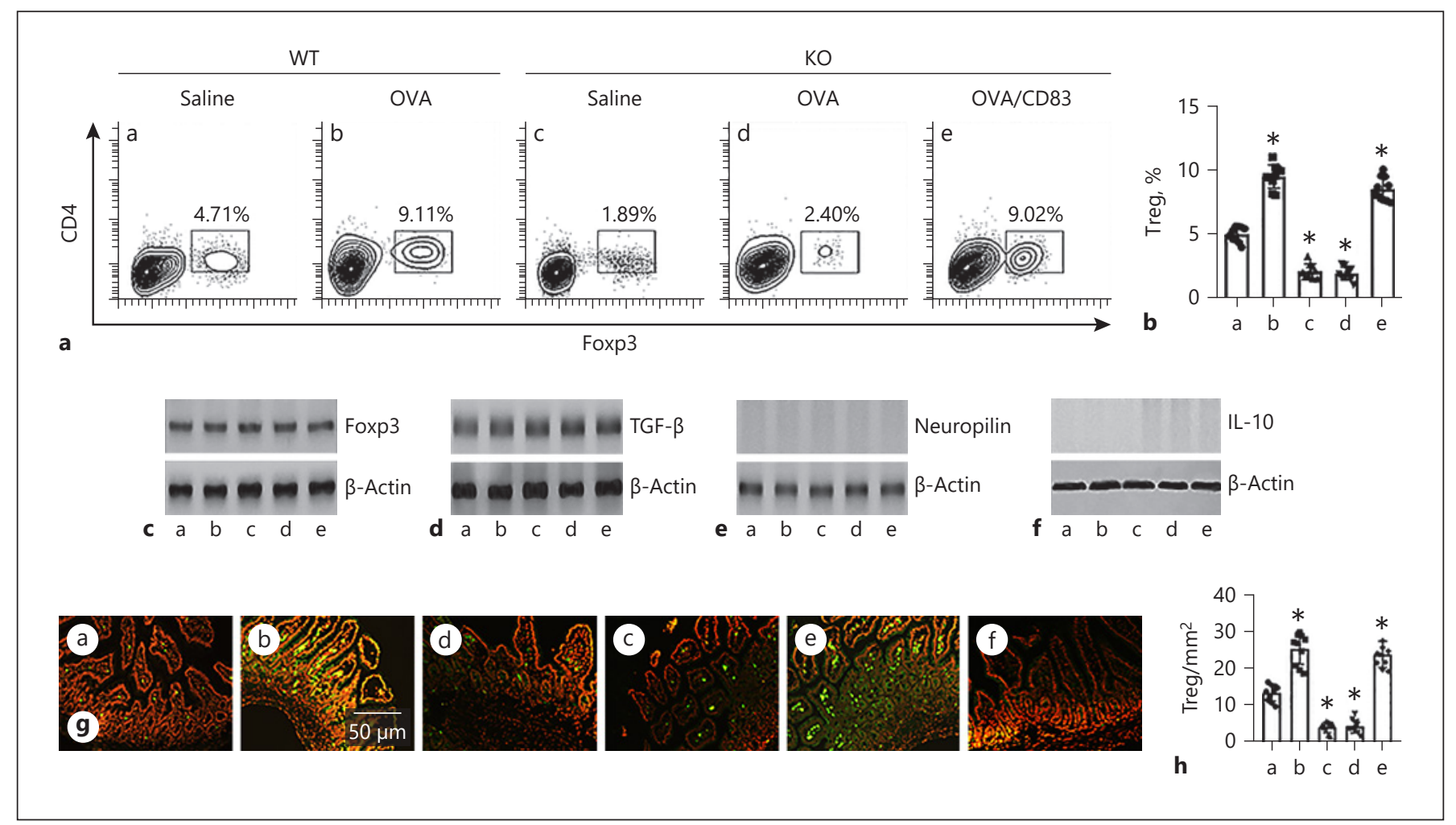

Fig. 3. IEC-derived CD83 is required in Treg generation. WT mice and $\mathrm{KO}$ mice (mice with CD83-deficient IEC) were gavage-fed with OVA ( $1 \mathrm{mg} / \mathrm{mouse}$ in $0.1 \mathrm{~mL}$ saline) or OVA + CD83 $(1 \mu \mathrm{g} /$ mouse) daily for 1 week. Small intestinal segments were excised from each mouse. LPMCs were prepared and analyzed by flow cytometry. Tregs were isolated from LPMCs and analyzed by Western blotting. a The gated plots show $\mathrm{CD} 4^{+}$Foxp $3^{+}$Tregs counts (these cells were also CD25+, not shown). b The bars show summarized Treg counts. c-f Tregs were isolated from the intestinal tissues; proteins were extracted from the Tregs and analyzed by Western blotting. The immunoblots show Foxp3 (c), TGF- $\beta$ (d), neuropilin (e), and IL-10 (f) proteins in isolated Tregs. $\mathbf{g}, \mathbf{h}$ Rep-

cantly fewer Treg counts were detected in $\mathrm{KO}$ mice. By concomitantly feeding with OVA and recombinant CD83 restored the Treg generation in KO mice (Fig. 3a, b). We further purified Tregs from the intestinal tissues; proteins were extracted from Tregs and analyzed by Western blotting. The results showed that Foxp 3 and TGF- $\beta$ proteins were detectable, while no neuropilin (an indicator of peripheral Treg [14]) and IL-10 were detected in the samples (Fig. 3c-f). The data were verified by immunohistochemistry that illustrated Tregs in the intestinal tissues (Fig. 3g, h); the Treg counts were in parallel with the results of flow cytometry (Fig. 3a, b). The results indicate that $\mathrm{CD} 83$ is required in the inducible $\mathrm{CD} 4^{+} \mathrm{Foxp}^{+}$Treg generation in the intestine by feeding with OVA.

CD83 Facilitates Treg Generation resentative immunohistochemistry images show Treg staining (in green) in the intestinal tissues. Bars show summarized Treg counts in the intestinal tissues. The data of bars are presented as mean \pm SEM of 10 mice per group. ${ }^{*} p<0.01$ (ANOVA followed by the Dunnett's test) compared with group a. Each sample was analyzed in triplicate. The group labels in each subpanel are the same as those in panel A. Sections in panel $\mathbf{g}$ - $\mathrm{f}$ were stained with isotype IgG and used as a negative control. Tregs, regulatory T cells; IECs, intestinal epithelial cells; WT, wild type; LPMC, lamina propria mononuclear cells; TGF, transforming growth factor; IL, interleukin; OVA, ovalbumin.

\section{CD83 Cooperates with OVA Induces TIEG1 \\ Expression in OVA-Primed CD4 $4^{+}$T Cells}

TGF- $\beta$-inducible early gene 1 (TIEG1) is a critical factor in the Treg differentiation [15]; we infer that CD83 upregulates the TIEG1 expression in $\mathrm{CD} 4^{+} \mathrm{T}$ cells based on the above results. To test this, $\mathrm{CD} 4^{+} \mathrm{T}$ cells were isolated from the naive BALB/c mouse spleen and exposed to recombinant CD83 (rCD83) at either 10 or $100 \mathrm{ng} / \mathrm{mL}$ in the culture for 24 or $48 \mathrm{~h}$; the TIEG1 expression in $\mathrm{CD}^{+} \mathrm{T}$ cells was analyzed by RT-qPCR and Western blotting. However, no appreciable changes of the TIEG1 expression were detected in $\mathrm{CD}^{+} \mathrm{T}$ cells (Fig. $4 \mathrm{a}, \mathrm{b}$ ). We then isolated $\mathrm{CD}^{+} \mathrm{T}$ cells from the DO11.10 mouse spleen (these cells are OVA antigen-primed); the cells 


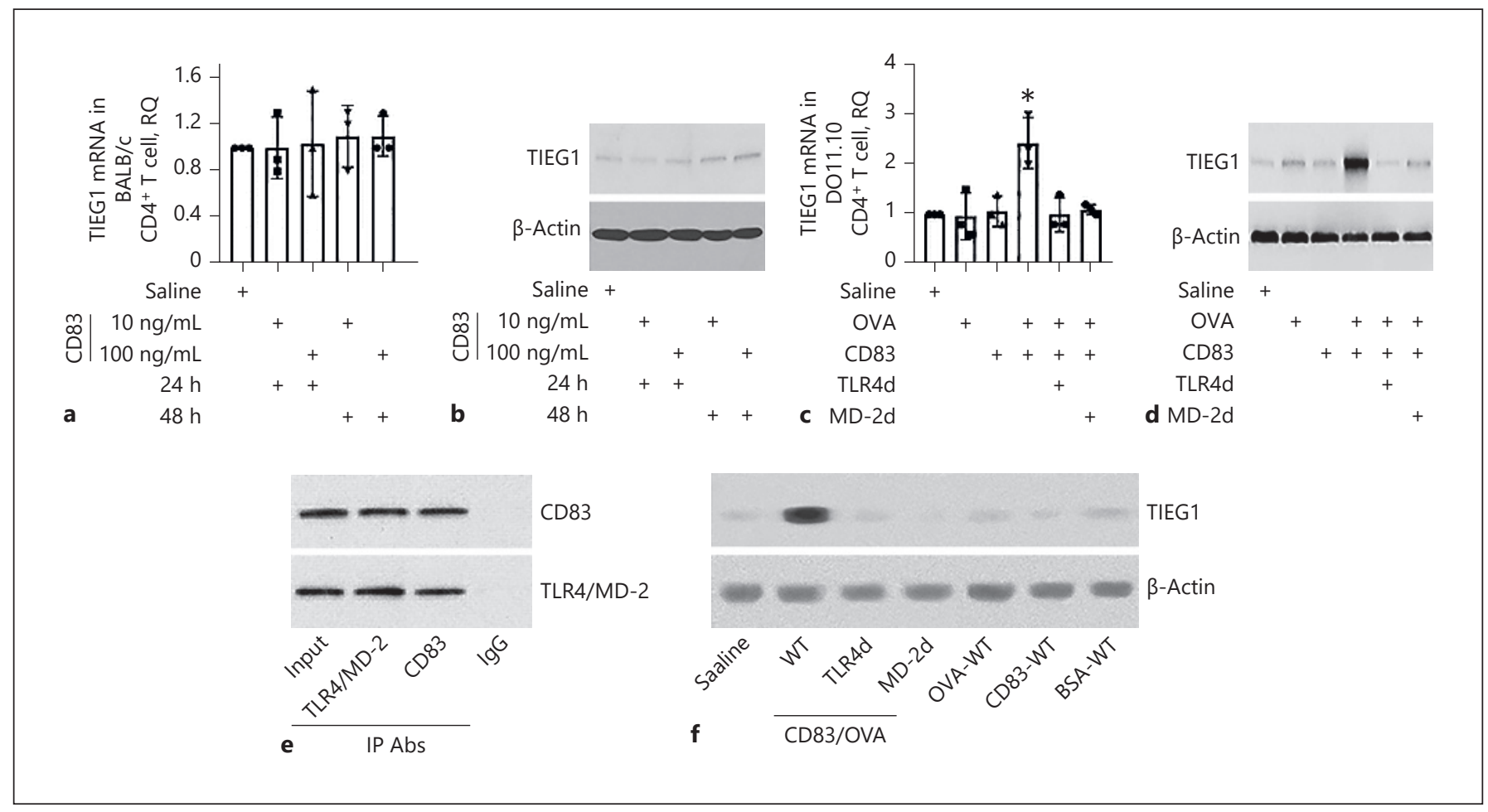

Fig. 4. CD83 modulates TIEG1 activities in antigen-primed CD4 ${ }^{+}$ $\mathrm{T}$ cells. BALB/c CD $4^{+} \mathrm{T}$ cells were exposed to CD83 at indicated concentrations and harvested at indicated time points. The bars show TIEG1 mRNA levels (a); the immunoblots show TIEG1 protein levels (b). DO11.10 CD4 ${ }^{+} \mathrm{T}$ cells were exposed to OVA or/and CD83 in the culture for $48 \mathrm{~h}$. The bars show TIEG1 mRNA levels in $\mathrm{BALB} / \mathrm{c} \mathrm{CD} 4^{+} \mathrm{T}$ cells $(\mathbf{c})$; the immunoblots show TIEG1 protein levels in DO11.10 CD4 ${ }^{+} \mathrm{T}$ cells (d). e Co-IP immunoblots show

were exposed to rCD83 or/and OVA in the culture in the presence of DCs. The cells were harvested $48 \mathrm{~h}$ later and analyzed by RT-qPCR and Western blotting. We found that exposure to both OVA and CD83, but not either OVA alone or CD83 alone, markedly enhanced the TIEG1 expression in DO11.10 CD4 ${ }^{+} \mathrm{T}$ cells (Fig. 4c, d). Since CD83 can bind the TLR4/MD-2 complexes in monocytes [16], we infer that TLR4/MD-2 complexes mediate the effects of CD83 on regulating TIEG1 expression in $\mathrm{CD}^{+} \mathrm{T}$ cells. To test this, the TLR4 or MD-2 expression in DO11.10 $\mathrm{CD}^{+} \mathrm{T}$ cells was depleted by the CRISPR approach (online suppl. Fig. 3, 4). The cells were exposed to OVA/CD83 in the culture for $48 \mathrm{~h}$. We found that depletion of either TLR4 or MD-2 abolished the TIEG1 expression in the CD4 $4^{+} \mathrm{T}$ cells (Fig. 4c, d). A complex of CD83 and the TLR4/MD-2 complex were detected in the $\mathrm{CD}^{+} \mathrm{T}$ cells (Fig. 4e). We further found that concomitant exposure to CD83 and OVA-induced TIEG1
CD83 binds to the TLR4/MD-2 complex in CD4 ${ }^{+} \mathrm{T}$ cells. $\mathrm{f}$ Immunoblots show the TIEG1 levels in nuclear protein extracts of $\mathrm{CD} 4^{+}$ $T$ cells. The data of bars are presented as mean \pm SEM of 3 experiments. ${ }^{*} p<0.01$ (ANOVA followed by the Dunnett's test), compared with the saline alone group. The data represent 3 independent experiments. Each sample was analyzed in triplicate. OVA, ovalbumin. translocation into the nuclei of $\mathrm{CD}^{+} \mathrm{T}$ cells as demonstrated by using nuclear protein extracts (Fig. $4 \mathrm{f}$ ), that is, required in Treg differentiation [15]. The results demonstrate that exposure to both specific antigen and CD83 induces TIEG1 expression in antigen-primed $\mathrm{CD} 4^{+} \mathrm{T}$ cells, which does not occur in nonprimed $\mathrm{CD} 4^{+} \mathrm{T}$ cells, or antigen-primed cells in the presence of either antigen alone or CD83 alone.

\section{Concomitant Exposure of Antigen-Primed $\mathrm{CD}^{+} \mathrm{T}$}

Cells to Antigen and CD83 Induces Antigen-Specific

Tregs

To test the effects of CD83 on the Treg induction, $\mathrm{CD} 4^{+}$ $\mathrm{CD} 25^{-} \mathrm{T}$ cells were isolated from the DO11.10 mouse spleen by flow cytometry cell sorting. The cells were cocultured with DCs in the presence of OVA or/and CD83 for 5 days and then, analyzed by flow cytometry. The results showed that exposure to both OVA and CD83 induced 


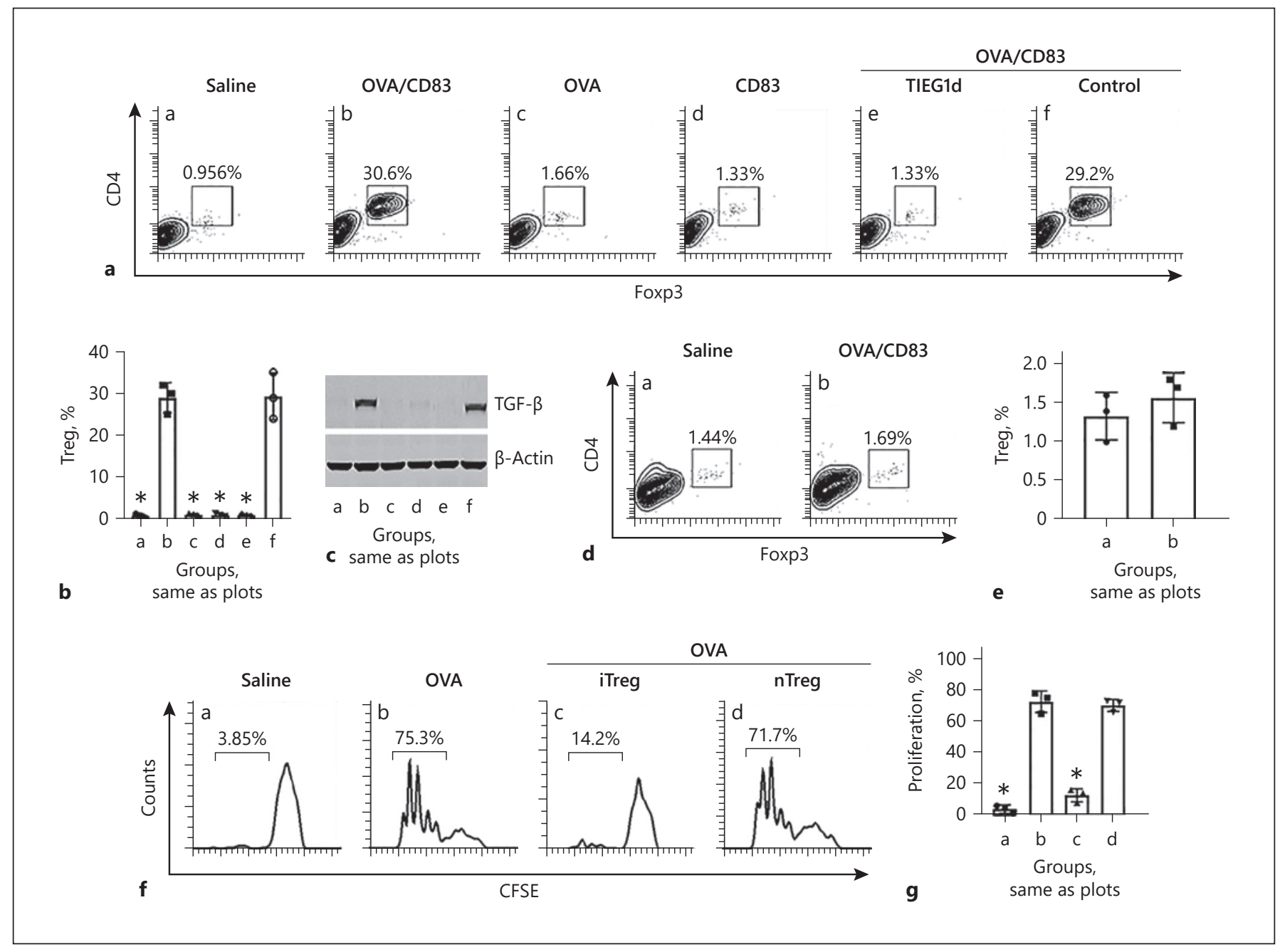

Fig. 5. Concomitant exposure to specific antigens and CD83 induces immune-competent Tregs. a, b CD $4^{+} \mathrm{CD} 25^{-} \mathrm{T}$ cells were isolated from the DO11.10 mouse spleen, cultured in the presence of DC, and exposed to reagents denoted above each subpanel. OVA: $20 \mu \mathrm{g} / \mathrm{mL}$. CD83: $1 \mu \mathrm{g} / \mathrm{mL}$. TIEG1d: TIEG1-deficient CD4 ${ }^{+}$ $\mathrm{T}$ cells (achieved by the CRISPR approach). Control: $\mathrm{CD} 4^{+} \mathrm{T}$ cells were treated with control CRISPR reagents. The gated plots show iTreg counts (the iTregs are also $\mathrm{CD} 25^{+}$, not shown). The bars show summarized Treg counts from 3 experiments. c Proteins were extracted from the $\mathrm{CD} 4^{+}$cells and were analyzed by Western blotting. The immunoblots show TGF- $\beta$ levels in the $\mathrm{CD} 4^{+} \mathrm{T}$ cells. d, e $\mathrm{CD} 4^{+} \mathrm{CD} 25^{-} \mathrm{T}$ cells were isolated from the BALB/c mouse spleen, cultured in the presence of DC, and exposed to saline or OVA/CD83 for 5 days. The gated plots show iTreg counts. The

about $30 \% \mathrm{CD}^{+} \mathrm{T}$ cells to differentiate into $\mathrm{CD} 4^{+} \mathrm{Foxp}^{+}$ Tregs; the cells were also expressed TGF- $\beta$, while exposure to either OVA alone or CD83 alone in the culture did not induce Treg development. Depletion of TIEG1 by RNAi abolished the CD83-induced Treg development (Fig. 5a-c; bars show summarized Treg counts from 3 experiments. f, $\mathbf{g} \mathrm{CD} 4^{+}$ $\mathrm{CD} 25^{-} \mathrm{T}$ cells were isolated from the DO11.10 mouse spleen; the cells were treated with the procedures denoted above each subpanel (in the presence of DC). OVA: $20 \mu \mathrm{g} / \mathrm{mL}$ in the culture (to induce $\mathrm{CD} 4^{+} \mathrm{T}$ cell proliferation and to activate iTregs). $\mathrm{nTreg}$ (isolated from $\mathrm{BALB} / \mathrm{c}$ mice). The gated histograms show proliferating OVA-specific $\mathrm{CD} 4^{+} \mathrm{T}$ cell counts. The bars show summarized proliferating $\mathrm{CD}^{+} \mathrm{T}$ cell counts of 3 experiments. The data of bars are presented as mean \pm SEM. Statistics: ANOVA followed by the Dunnett's test. Each sample was analyzed in triplicate. Tregs, regulatory T cells; DC, dendritic cells; TGF, transforming growth factor; OVA, ovalbumin; iTreg, inducible Treg; nTreg, natural Treg.

online suppl. Fig. 5). The results were verified by further experiments. Exposure of naive $\mathrm{BALB} / \mathrm{c} \mathrm{CD} 4^{+} \mathrm{T}$ cells to both OVA and CD83 in the culture did not induce to differentiate into Tregs (Fig. 5d, e), indicating that CD83 only facilitates the antigen-specific Treg development. 


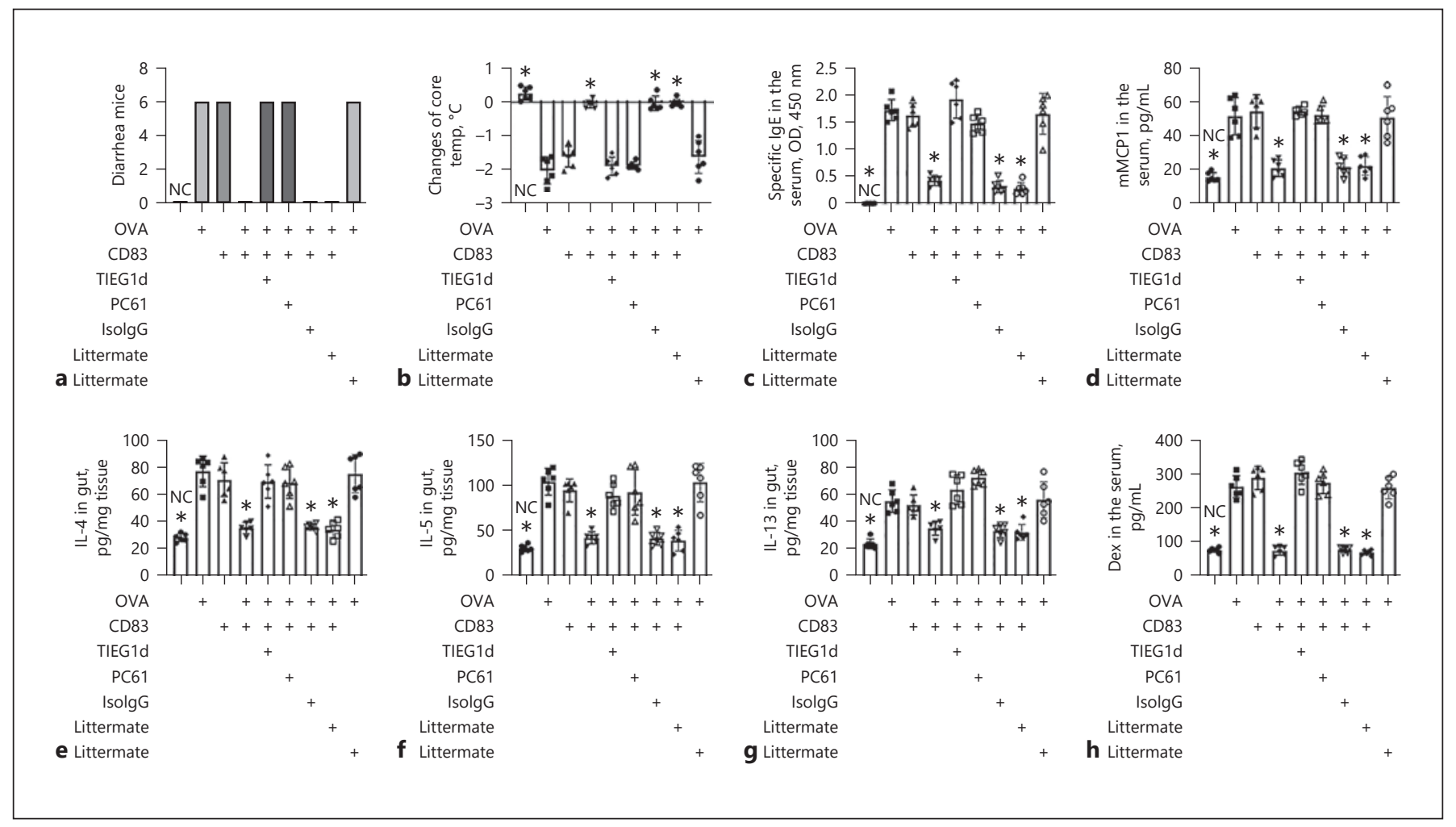

Fig. 6. Concomitant administration of OVA and CD83 suppresses experimental FA response. An FA BALB/c mouse model was developed with OVA as the specific antigen. The table below bars shows the treatment and conditions. NC: naive control mice. OVA or CD83: mice were fed with OVA or CD83. TIEG1d: mice with TIEG1-deficient CD4 ${ }^{+} \mathrm{T}$ cells. PC61 (or isoIgG): Mice were injected with anti-CD25 Ab or isotype IgG. Bars show FA response, including diarrhea (a), core temperature (Temp) changes (b), se- rum specific IgE (sIgE; c), serum mouse mast cell protease-1 (mMCP1; d), Th2 cytokine levels in intestinal tissue protein extracts $(\mathbf{e}-\mathbf{g})$, and serum dextran levels (h). Littermate: littermates of TIEG1 KO mice. The data of bars are means \pm SEM of 6 mice per group. ${ }^{*} p<0.01$ (ANOVA followed by the Dunnett's test), compared with the FA alone group. FA, food allergy; NC, naive control; OVA, ovalbumin.

\section{Immunotherapy with CD83 and Specific Antigen}

Suppresses Experimental FA via Inducing Tregs

We then assessed the effects of concurrent administration of CD83 and OVA (a specific antigen) on suppressing experimental FA. A BALB/c mouse FA model was developed with OVA as the specific antigen. The mice showed FA response, including diarrhea and a core temperature decline in response to OVA challenge, high levels of serum specific IgE and mouse mast cell protease-1 (mMCP1), and high Th2 cytokine levels in the intestinal tissues, and disrupted intestinal barrier function (Fig. 6). Administration of both CD83 and OVA, but not either CD83 alone or OVA alone, markedly suppressed the FA response, which was abolished by depletion of either the TIEG1 expression in $\mathrm{CD} 4^{+} \mathrm{T}$ cells (online suppl. Fig. 6) or depleting Tregs by injection of anti-CD25 Ab (Fig. 6). Meanwhile, we observed that concurrent administration 
of CD83 and OVA significantly increased Treg frequency in the FA mouse intestinal tissues that were blocked by depletion of TIEG1 expression (online suppl. Fig. 7). The results demonstrate that concurrent administration of both CD83 and specific antigens can inhibit experimental FA via inducing Tregs in the intestine.

\section{Discussion}

The present data show that IECs express CD83; its levels are markedly lower in sensitized mice than that in $\mathrm{NC}$ mice. Mice with CD83-deficient IECs fail to induce Tregs in the intestinal tissues, suggesting that CD83 plays a critical role in the Treg differentiation in the intestine. Concomitant exposing antigen-primed $\mathrm{CD} 4^{+} \mathrm{T}$ cells to $\mathrm{CD} 83$ and the specific antigens induce Treg development. Treating mice with both CD83 and the specific antigens via gavage-feeding can efficiently suppress experimental FA. It is noteworthy that passing through the stomach did not affect the bioactivities of CD83 as shown by the present data.

CD83 was first found in DCs and regarded as one of the indicators of DC activation [13]. Latter, it was found that not only DCs express CD83, other immune cells, such as T cells, B cells, macrophages, and mast cells also expressed CD83 [17]. Our data are in line with the previous reports [17], CD83 was also found in DCs, CD4 ${ }^{+} \mathrm{T}$ cells, B cells, macrophages, mast cells, and eosinophils. Furthermore, we found that IECs expressed CD83 that played a critical role in the Treg generation. Thus, our data have enriched the studies in the areas of CD83 and Treg generation.

It is recognized that DCs and Tregs play a central role in the oral tolerance establishment [18]. Upon activation, Tregs release immune regulatory mediators, such as TGF- $\beta$, to suppress other immune cell activities to keep the immune reactions within proper scope. The role of DCs in immune tolerance is that DCs induce Tregs; these DCs are designated tolerogenic DCs. It is found that IECs also have immune tolerogenic functions [6]. IECs express MHC II and can present antigen information to CD $4^{+} \mathrm{T}$ cells. Previous studies thought that IECs did not express CD80 or CD86, thus, could not complete the antigen-presentation to T cells [6]. The present data compensate this weak point of IEC by revealing that IECs express CD83, another costimulatory molecule used that is recognized in DCs. The data also show that CD83 can activate antigen-primed $\mathrm{CD} 4^{+} \mathrm{T}$ cells in cooperating with specific antigens; such an action results in the TIEG1 expression in primed $\mathrm{CD} 4^{+} \mathrm{T}$ cells. TIEG1 plays an important role in the Treg generation [15]. Our data are consistent with the report by showing that $\mathrm{CD} 83$ and specific antigen induce the primed $\mathrm{CD} 4^{+} \mathrm{T}$ cells, but not naive $\mathrm{CD} 4^{+} \mathrm{T}$ cells, to differentiate into Tregs. Since Tregs are the most important component in the immune tolerance system [19], the present data demonstrate that IECs contribute to antigen-specific oral tolerance by inducing antigen-specific Tregs via the CD83/specific antigen/TIEG1/Foxp3 pathway.

It has been found that soluble CD83 (sCD83) had immune regulatory functions [20]. Our recent publications show that $\mathrm{SCD} 83$ suppresses Th2 response [21]. Royzman et al. [10] found that administration of sCD83 could inhibit rheumatoid arthritis in an sCD83/indoleamine-2, 3 -dioxygenase/TGF- $\beta$-dependent manner. The present data show that CD83 was also involved in upregulating the TGF- $\beta$ expression in $\mathrm{CD} 4^{+} \mathrm{T}$ cells in cooperating with the presence of specific antigens. This is like the antigenpresentation process, in which 2 activation signals are required. One is the specific antigens presented by the MHC II/antigen complexes, which bind to the antigen-specific TCR; another is the costimulators, CD80 or CD86; the latter binds to CD28 and CTLA-4 on the cell surface to activate $\mathrm{CD} 4^{+} \mathrm{T}$ cells. The antigen-presentation process cannot be completed in the absence of either of the activating signals. Similar phenomena were found in the present study. Our data show that both CD83 and specific antigens (in the presence of DC) are required in inducing antigen-specific Tregs. Tregs were not induced in lacking of either one.

The data show that mice with CD83-deficient IECs fail to induce Tregs in the intestinal tissues. The data mirror the crucial effects of CD83 on the Treg generation by feeding with OVA. OVA is a food protein and commonly used as a model antigen in the immunological studies. It is known that consecutively exposure to a small dose of OVA induces immune tolerance by inducing Treg differentiation [22]. Our data are in line with the previous studies by showing that feeding mice with OVA daily for 7 days induced the Treg generation in the intestine; however, it did not occur in mice with CD83-deficient IECs. The data emphasize that IEC-derived CD83 is required in the Treg generation under physiological condition. Indeed, our further experiments showed that exposure to CD83 and OVA in the presence of DC induced TIEG1 expression in OVA-primed $\mathrm{CD} 4^{+} \mathrm{T}$ cells, but not in those nonprimed $\mathrm{CD}^{+}{ }^{+} \mathrm{T}$ cells, such as naive $\mathrm{CD} 4^{+} \mathrm{T}$ cells isolated from $\mathrm{BALB} / \mathrm{c}$ mice. Furthermore, exposure to either OVA alone or CD83 alone did not have any effects on 
inducing TIEG1 expression in OVA-primed CD4 ${ }^{+} \mathrm{T}$ cells as shown by the present data. To produce, TGF- $\beta$ is the milestone in Treg generation. TIEG1 plays a critical role in promoting the TGF- $\beta$ expression [15]. The present results showed that the CD83 expression in IECs is lower in sensitized mice. A smaller number of Tregs was recognized in FA subjects as compared to normal controls, which is a critical causative factor in the FA development [23]. Our data provide mechanistic evidence that the lower CD83 expression in IECs may be one of the reasons causes a small number of Treg in the intestine under FA environment. Further studies are required to elucidate the causative factors and mechanisms about the low CD83 levels in IECs.

The data showed that concomitant administration of CD83 and specific antigen, OVA, efficiently suppressed FA response in a murine model. The Treg generation in the intestine played a central role in the FA inhibition. There have been many studies focusing on generating Tregs to be used in the inhibition of immune disorders, among which Tregs were generated in vitro and transfused into subjects with immune disorders [7]. A weak point of this approach is that the Tregs, the so-called living drugs, only survive in recipients for a short time [24]. The present method is to generate Tregs in vivo to restore the immune tolerance in subjects with immune disorders [7], such as the FA. This is expected to overcome the weak point of Treg transfusion [24]. Another critical point in the Treg therapy is the antigen specific. As shown by the present data, generated Tregs can be activated by exposure to specific antigens and then, elicit the immune-suppressive functions. Such a merit greatly reduces the nonspecific immune suppression compared to polyclonal Tregs [7].

In conclusion, in the present study, we found that IECs expressed CD83 that was significantly less in FA IECs than that in NC IECs. CD83-deficiency in IECs retarded the Treg generation in the intestine. Exposure of antigenprimed $\mathrm{CD} 4^{+} \mathrm{T}$ cells to both $\mathrm{CD} 83$ and specific antigens, but not either one alone, induced antigen-specific Tregs. Administration of both CD83 and specific antigens, but not either one alone, efficiently suppressed FA response in a murine model by inducing Tregs in the intestinal tissues. The data suggest that the concurrent administration of CD83 and specific antigens have translational potential for the treatment of FA and other allergic disorders.

\section{Acknowledgements}

This study was supported by grants of the National Nature and Science Foundation of China (81870706, 31570932, 81970491, and 82071807), Guangdong Provincial Key Laboratory of Regional Immunity and Diseases (2019B030301009), Cross Innovation Research Initiative Funds of Shenzhen University and Shenzhen science, technology, and innovation committee (KQTD20170331145453160 and KQJSCX20180328095619081).

\section{Statement of Ethics}

The animal experimental procedures were approved by the Animal Ethical Committee at Zhengzhou University.

\section{Conflict of Interest Statement}

There are no conflicts of interest.

\section{Author Contributions}

Y.Y., Q.R.J., Y.M., J.Q.L., Z.Q.L., and S.W. performed experiments, analyzed data, and reviewed the manuscript. P.C.Y., P.Y.Z., and Z.G.L. organized the study and supervised experiments. P.C.Y. designed the project and prepared the manuscript.

\section{References}

1 Yu W, Freeland DMH, Nadeau KC. Food allergy: immune mechanisms, diagnosis and immunotherapy. Nat Rev Immunol. 2016; 16(12):751-65.

2 Du Toit G, Sayre PH, Roberts G, Sever ML, Lawson K, Bahnson HT, et al. Effect of avoidance on peanut allergy after early peanut consumption. N Engl J Med. 2016;374(15):143543.
3 Du Toit G, Roberts G, Sayre PH, Bahnson HT, Radulovic S, Santos AF, et al. Randomized trial of peanut consumption in infants at risk for peanut allergy. N Engl J Med. 2015;372(9): 803-13.

4 Sicherer SH, Sampson HA. Food allergy: a review and update on epidemiology, pathogenesis, diagnosis, prevention, and management. J Allergy Clin Immunol. 2018;141(1):41-58.

5 Chinthrajah RS, Hernandez JD, Boyd SD, Galli SJ, Nadeau KC. Molecular and cellular mechanisms of food allergy and food tolerance. J Allergy Clin Immunol. 2016;137(4):984-97.
6 Mowat AM. Anatomical basis of tolerance and immunity to intestinal antigens. Nat Rev Immunol. 2003;3(4):331-41.

7 Ferreira LMR, Muller YD, Bluestone JA, Tang Q. Next-generation regulatory T cell therapy. Nat Rev Drug Discov. 2019;18(10):749-69.

8 Charbonnier LM, Cui Y, Stephen-Victor E, Harb H, Lopez D, Bleesing JJ, et al. Functional reprogramming of regulatory $\mathrm{T}$ cells in the absence of Foxp3. Nat Immunol. 2019;20(9): 1208-19. 
9 Breloer M, Fleischer B. CD83 regulates lymphocyte maturation, activation and homeostasis. Trends Immunol. 2008;29(4):186-94.

10 Royzman D, Andreev D, Stich L, Rauh M, Bauerle T, Ellmann S, et al. Soluble CD83 triggers resolution of arthritis and sustained inflammation control in IDO dependent manner. Front Immunol. 2019;10:633.

11 Amobi A, Qian F, Lugade AA, Odunsi K Tryptophan catabolism and cancer immunotherapy targeting IDO mediated immune suppression. Adv Exp Med Biol. 2017;1036: 129-44.

12 Liu H, Mintern JD, Villadangos JA. MARCH ligases in immunity. Curr Opin Immunol. 2019;58:38-43.

13 Li Z, Ju X, Silveira PA, Abadir E, Hsu WH, Hart DNJ, et al. CD83: activation marker for antigen presenting cells and its therapeutic potential. Front Immunol. 2019;10:1312.

14 Yadav M, Louvet C, Davini D, Gardner JM, Martinez-Llordella M, Bailey-Bucktrout S, et al. Neuropilin-1 distinguishes natural and inducible regulatory $\mathrm{T}$ cells among regulatory $\mathrm{T}$ cell subsets in vivo. J Exp Med. 2012;209(10): 1713-9. s1-19.
15 Venuprasad K, Huang H, Harada Y, Elly C, Subramaniam M, Spelsberg T, et al. The E3 ubiquitin ligase Itch regulates expression of transcription factor Foxp3 and airway inflammation by enhancing the function of transcription factor TIEG1. Nat Immunol. 2008; 9(3):245-53.

16 Horvatinovich JM, Grogan EW, Norris M Steinkasserer A, Lemos H, Mellor AL, et al. Soluble CD83 inhibits $\mathrm{T}$ cell activation by binding to the TLR4/MD-2 complex on CD14(+) monocytes. J Immunol. 2017; 198(6):2286-301.

17 Fujimoto Y, Tedder TF. CD83: a regulatory molecule of the immune system with great potential for therapeutic application. J Med Dent Sci. 2006;53(2):85-91.

18 Mowat AM. To respond or not to respond: a personal perspective of intestinal tolerance. Nat Rev Immunol. 2018;18(6):405-15.

19 Tordesillas L, Berin MC. Mechanisms of oral tolerance. Clin Rev Allergy Immunol. 2018; 55(2):107-17.

20 Zinser E, Naumann R, Wild AB, Michalski J, Deinzer A, Stich L, et al. Endogenous expression of the human CD83 attenuates EAE symptoms in humanized transgenic mice and increases the activity of regulatory $\mathrm{T}$ cells. Front Immunol. 2019;10:1442.
$21 \mathrm{Wu}$ YJ, Song YN, Geng XR, Ma F, Mo LH, Zhang XW, et al. Soluble CD83 alleviates experimental allergic rhinitis through modulating antigen-specific Th2 cell property. Int J Biol Sci. 2020;16(2):216-27.

22 Hammerschmidt-Kamper C, Biljes D, Merches K, Steiner I, Daldrup T, Bol-Schoenmakers $\mathrm{M}$, et al. Indole-3-carbinol, a plant nutrient and AhR-Ligand precursor, supports oral tolerance against OVA and improves peanut allergy symptoms in mice. PLoS One. 2017; 12(6): 0180321.

23 Noval Rivas M, Burton OT, Wise P, Charbonnier LM, Georgiev P, Oettgen HC, et al. Regulatory $\mathrm{T}$ cell reprogramming toward a Th2cell-like lineage impairs oral tolerance and promotes food allergy. Immunity. 2015;42(3): 512-23.

24 Singh K, Stempora L, Harvey RD, Kirk AD, Larsen CP, Blazar BR, et al. Superiority of rapamycin over tacrolimus in preserving nonhuman primate treg half-life and phenotype after adoptive transfer. Am J Transplant. 2014;14(12):2691-703. 